\title{
Obstetrics and Gynecology Ultrasound Topics in Family Medicine Resident Training
}

\author{
Jennifer Molokwu
}

\begin{abstract}
Access to timely and appropriate prenatal and maternity care is widely known to be an important factor in improving birth outcomes. Family physicians make a significant contribution to the provision of prenatal care in the United States. The amount of exposure to maternity care and prenatal procedures in residency increase likelihood of incorporation of prenatal care in future practice. The use of prenatal ultrasounds has become standard in the management of pregnancy. Ultrasonography has wide application in obstetric care and is being used in screening and diagnosis during antenatal, intrapartum and postpartum periods. Family physicians that provide obstetric care should be trained to carry out basic obstetric ultrasound scans. In our paper, we have outlined an approach to the incorporation of ultrasound training into Family Medicine residency education. We have also explored the use of simulation as an adjunct to scanning live patients in a training curriculum.
\end{abstract}

Keywords: Family medicine, Obstetrics, Ultrasound, Residency education.

How to cite this article: Molokwu J. Obstetrics and Gynecology Ultrasound Topics in Family Medicine Resident Training. Donald School J Ultrasound Obstet Gynecol 2014;8(1):31-34.

Source of support: Nil

Conflict of interest: None

\section{INTRODUCTION}

Access to timely and appropriate prenatal and maternity care is widely known to be an important factor in improving birth outcomes. In the United States (US), women living in rural areas have less access to an obstetrician and are more likely to initiate prenatal care at a later stage of their pregnancy. This pattern occurs nationwide and in a majority of states. ${ }^{1,2}$ Twenty-nine percent (29\%) of females residing in rural areas live in counties without access to obstetrics and gynecology care. ${ }^{2,3}$

Historically, the scope of Family Medicine has included the care of the female patient over her lifetime; therefore, the provision of quality maternal and child care remains

\section{Assistant Professor}

Department of Family and Community Medicine, Paul L Foster School of Medicine, Texas Tech University Health Sciences Center at El Paso, Texas, USA

Corresponding Author: Jennifer Molokwu, Assistant Professor, Department of Family and Community Medicine Paul L Foster School of Medicine, Texas Tech University Health Sciences Center, 9849 Kenworthy St, EI Paso, TX 79924, USA Phone: 9157573178, e-mail: jennifer.molokwu@ttuhsc.edu integral to the practice of Family Medicine in the US. In recent estimates, approximately 30 to $35 \%$ of family physicians still include prenatal and obstetric care as part of their practice. ${ }^{4,5}$ In many rural areas of the US, a significant portion of maternity care is provided by family physicians, with consultation and support of obstetricians and gynecologists. ${ }^{6}$ Due to the continued important role of family physicians, especially in rural areas, in the provision of prenatal and maternity care, the Society of Teachers in Family Medicine (STFM) as well as the American Academy of Family Physicians (AAFP) continues to encourage the development of the curricula that teaches proficiency and competency in obstetrics. ${ }^{7,8}$ In recent times, however, there has been a declining interest in the provision of obstetrics by family physicians, mostly as a result of concerns from physicians of longer work hours, additional malpractice cost and ongoing necessity for additional training. ${ }^{9}$ In a follow-up study by Ratcliffe et al evaluating obstetric care training in family practice residencies, it was observed that having family physicians who provided obstetric care as well as the ability to do other prenatal procedures, increased the likelihood of residents providing maternity care following the completion of their training. ${ }^{10}$

In recent times, the use of prenatal ultrasounds has become the standard in management of pregnancy and the detection of complications arising from this state. Images obtained from routine obstetrical ultrasounds can be used to determine gestational age, assess for congenital anomalies and monitor fetal growth during the perinatal period. During delivery, ultrasound images can be used to rapidly confirm fetal positioning and assess for complications. In high-risk pregnancies, ultrasound technology can assist in the evaluation of fetal blood flow velocity and the detection of fetal cardiovascular abnormalities. In addition, ultrasound technology also assists with the measurement of blood flow through fetal, umbilical and uterine arteries to diagnose potential risks for intrauterine growth restriction. Prenatal ultrasounds can also be used to evaluate fetal well-being, when coupled with external fetal heart rate monitoring (biophysical profile). Ultrasound is also used in guidance of diagnostic and therapeutic procedures, such as amniocentesis or cordocentesis. Given the breath of the use of this technology in the care of the pregnant woman, it is 
imperative that family physicians are exposed to training in prenatal ultrasonography as part of their obstetric curriculum in residency.

\section{Core Ultrasound Skills in Residency Training}

The Accreditation Council on Graduate Medical Education (ACGME) requires that each resident in a Family Medicine Program should be capable of managing a normal pregnancy and delivery. Residents should also be trained in the recognition and initial management of the high-risk patient, including consultation and referral. ${ }^{11}$ The ACGME also felt that where appropriate for resident's future practice and patient care, the resident must be trained in the management of the high-risk pregnant patient.

While specific guidelines exist for the duration and content of the experience in maternity care, there are currently no set guidelines on training for prenatal ultrasounds.

In 2007 and again in 2008, the STFM group on Hospital Medicine and Procedural Training met to define a list of core procedures recommended within the scope of Family Medicine training. For training in obstetric ultrasound, the group recommended that all graduating residents should be able to perform a basic obstetric ultrasound independently. Residents should be able to obtain a basic fetal biometry, assess AFI (amniotic fluid index), determine fetal presentation and document placental location. ${ }^{8}$ It is also recommended that residents should have the opportunity to train in ultrasound dating and fetal anatomy survey. In a position paper on the training and credentialing of family physicians in diagnostic obstetrics and gynecology ultrasonography updated in 2008, the AAFP emphasized the importance of training in diagnostic ultrasound examination by family physicians. The AAFP also highlighted the necessity for family physicians involved in the care of pregnant women should develop skills needed for prenatal diagnosis of fetal anomalies, estimation of gestational age, identification of fetal growth abnormalities, assessment of fetal well-being, evaluation of antenatal hemorrhage and evaluation of intrapartum complications. ${ }^{12}$

Conner et al surveyed program directors of Family Medicine residencies and found relatively high use of ultrasounds, especially in those programs that provided obstetric care and documented a broad interest $(45 \%$ of respondents regardless of provision of prenatal care) in the establishment of an obstetric ultrasound curriculum. ${ }^{13}$

\section{Training Methodology}

As of today, a standard training curriculum for teaching basic obstetric ultrasounds in Family Medicine residency does not exist. The most common approaches evaluated in literature involve didactics followed by supervised scanning and some form of competency-based testing. ${ }^{13-15}$

Methods of delivery of didactic sessions have varied from intense instructional courses spanning several days to longitudinal sessions over 1 to 3 years of residency, with some including online or CD-ROM self-study modules. Regardless of the methodology used in the delivery of these didactics, it is reasonable that these sessions cover the following areas:

1. Ultrasound physics, terminology and knobology

2. Machine usage: acquiring and capturing images

3. Anatomy of relevant structures

4. Indications for obstetric ultrasound

5. Practice management: billing and coding for in-office ultrasounds

Following a review of readings, combined with didactic instructions and an introduction to the equipment with the learners, supervised scanning of patients allows learners to develop the manual dexterity required to obtain high quality images. Equally important, learners must not only achieve competence in obtaining images but also in interpreting images obtained. When dealing with learners, mechanisms should be in place in order to ensure the quality of images and the correct interpretation of these images. Usually, all scans during this period should be under direct supervision. The International Society of Ultrasound in Obstetrics and Gynecology (ISUOG) and the American Institute of Ultrasound Medicine (AIUM) provided detailed guidelines as to the content of the obstetric ultrasound exam and what should be included in the documentation. ${ }^{16,17}$

There has been some debate over the number of scans required to achieve competency in the obstetric ultrasound. Studies completed in Family Medicine education settings to evaluate process and outcome measures have shown that competency can be achieved in 25 to 50 scans. ${ }^{13-15,18}$

\section{Clinical Simulation}

Over the last several decades there has been a lot of advancement and interest in the use of clinical simulation for teaching and evaluation of procedural skills in both residency and medical student education. Simulation has been shown to increase competency of learners in specific skills and/or procedures. ${ }^{19}$ Clinical simulators have also been documented to increase the confidence of learners in performing acquired skills. ${ }^{20,21}$ Much of the newer ultrasound simulators allow for the display of normal and abnormal fetal scans in real time. This gives the learner the ability to view images that correspond in real time with the position of the transducer and perform complete prenatal scans with integration of biometry. 
The advantages of using simulation in ultrasound training include the following:

- Ability for learners to practice techniques multiple times without discomfort or harm to patients.

- Allows learner to view relatively rare conditions and

- Ability to assess the learners acquired skills in a standardized method.

Clinical simulation has already become an important tool in graduate and postgraduate medical education and could assist in meeting requirements for evaluation and documentation of specific competencies for physicians in training.

\section{Documenting Demonstrated Proficiency}

In recent times, the ACGME and the Family Medicine Residency Review Committee (RRC) have adopted an approach to accreditation that is outcome-based. Training programs must therefore provide the documentation of both the training process and assessment of competency of the trainees. While the prenatal obstetrical scan is not designated as a core procedure in Family Medicine residency training, it is reasonable to develop similar standards for any skill or procedure taught during training.

Competency as defined by McConnell is 'an observable ability of a health professional to integrate multiple components, such as knowledge, skills, values and attitudes'. ${ }^{22}$ To evaluate resident physician's competency in performing prenatal ultrasounds, we should be able to document that he or she has achieved proficiency in the following areas:

- Knowledge: Understanding the anatomical and physiological process of pregnancy as well as indications for sonographic exam and imaging parameters. AIUM, ACOG and the American College of Radiology (ACR) defined the standard content of the routine obstetrical examinations, which can be used to create standard testing parameters.

- Technical skills: Demonstrate the ability to acquire appropriate and interpretable images in a reproducible manner.

- Cognitive skills: Ability to interpret sonograms reliably.

- Management skills: Ability to apply findings to patient's clinical presentation.

The documentation of procedure needs to incorporate organized course work as well as direct observation of technical skills and a minimum number of required scans. Again, simulated clinical encounters can be useful in assessing skills acquisition in a standardized manner in this area.

\section{CONCLUSION}

Family Medicine physicians continue to contribute significantly to obstetrical care in the US, especially among rural and underserved women. Given the growing importance of ultrasound technology in the management of the pregnant female, it is crucial that these skills are taught to family physicians while undergoing training. We have discussed two key principles in our paper: first, an approach to incorporate ultrasound training into Family Medicine resident education and, second, a recommendation to use simulation as an adjunct to scanning live patients.

\section{REFERENCES}

1. Larson EH, Hart LG, Rosenblatt RA. Is non-metropolitan residence a risk factor for poor birth outcome in the US? Soc Sci Med 1997;45(2):171-188.

2. University of Washington Rural Health Research Center. Poor birth outcome in rural United States: 1985-1987 to 1995-1997 final report no. 119. Available at: http://depts.washington.edu/ uwrhrc/uploads/RHRC_FR119_larson.pdf. Updated 2008. Accessed on May 01, $20 \overline{13}$.

3. American Congress of Obstetricians and Gynecologists (ACOG), Committee on Health Care for Underserved Women. Health disparities for rural women. Available at: http://www. acog.org/Resources $\% 20$ And\%20Publications/Committee $\% 20$ Opinions/Committee $\% 20$ on $\% 20$ Health $\% 20$ Care $\% 20$ for $\% 20$ Underserved $\% 20$ Women/Health\%20Disparities $\% 20$ for $\% 20$ Rural\%20Women.aspx. Updated 2012. Accessed May 5, 2013.

4. Cohen D, Guirguis-Blake J, Jack B. Family physicians make a substantial contribution to maternity care: The case of the state of maine. Am Fam Physician 2003;68(3):405.

5. Ratcliffe SD, Newman SR, Stone MB, Sakornbut E, Wolkomir M, Thiese SM. Obstetric care in family practice residencies: A 5-year follow-up survey. The Journal of the American Board of Family Practice 2002;15(1):20-24.

6. Barclay AM, Knapp DP, Kallail KJ. The provision of labor and delivery services by graduates of four kansas family practice residencies. Kans Med 1996;97(1):19-23.

7. AAFP. Maternal/child care (obstetrics/prenatal care). Available at: http://www.aafp.org/online/en/home/policy/policies/m/ maternal.html\#.UXq2fuEjuv4.email. Updated 2012. Accessed on May 5, 2013.

8. Kelly BF, Sicilia JM, Forman S, Ellert W, Nothnagle M. Advanced procedural training in Family Medicine: A group consensus statement. Fam Med 2009;41(6):398-404.

9. Cohen D, Coco A. Declining trends in the provision of prenatal care visits by family physicians. Ann Fam Med 2009;7(2):128133.

10. Ratcliffe SD, Newman SR, Stone MB, Sakornbut E, Wolkomir M, Thiese SM. Obstetric care in family practice residencies: A 5-year follow-up survey. The Journal of the American Board of Family Practice 2002;15(1):20-24.

11. Accreditation Council on Graduate Medical Education. ACGME program requirements for graduate medical education in Family Medicine. Available at: www.acgme.org/acgmeweb/Portals/0/ PFAssets/.../120pr07012007.pdff. Updated 2011. Accessed on May 2, 2013. 
12. AAFP Position Paper. Ultrasonography, diagnostic in OB/GYN (position paper). Available at: http:/www.aafp.org/online/en/ home/policy/policies/u/ultrasonography.html\#.UXqybmZU-dI. email. Updated 2008. Accessed May 2, 2013.

13. Connor PD, Deutchman ME, Hahn RG. Training in obstetric sonography in Family Medicine residency programs: Results of a nationwide survey and suggestions for a teaching strategy. J Am Board Fam Pract 1994;7(2):124-129.

14. Hahn RG, Roi LD, Ornstein SM. Obstetric ultrasound training for family physicians. results from a multi-site study. J Fam Pract 1988;26(5):553-558.

15. Keith R, Frisch L. Fetal biometry: A comparison of family physicians and radiologists. Family Medicine Kansas City 2001;33(2):111-114.

16. American Institute of Ultrasound in Medicine. AIUM practice guideline for the performance of obstetric ultrasound examinations. J Ultrasound Med 2010;29:157-166.

17. Salomon LJ, Alfirevic Z, Berghella C, Bilardo K, Johnsen SL, Kalache K, Leung KY, MalingerMunoz F. Prefumo F, Toi A Lee W. Practice guidelines for performance of the routine mid- trimester fetal ultrasound scan. Ultrasound Obstet Gynecol 2011;37:116-126.

18. Smith CB, Sakornbut EL, Dickinson LC, Bullock GL. Quantification of training in obstetrical ultrasound: A study of family practice residents. Journal of Clinical Ultrasound 1991;19(8):479-483.

19. Girzadas Jr DV, Antonis MS, Zerth H, et al. Hybrid simulation combining a high fidelity scenario with a pelvic ultrasound task trainer enhances the training and evaluation of endovaginal ultrasound skills. Acad Emerg Med 2009;16(5):429-435.

20. Maul H, Scharf A, Baier P. Ultrasound simulators: Experience with the SonoTrainer and comparative review of other training systems. Ultrasound Obstet Gynecol 2004;24(5):581-585.

21. Okuda Y, Bryson EO, DeMaria S. The utility of simulation in medical education: What is the evidence? Mount Sinai Journal of Medicine: A Journal of Translational and Personalized Medicine 2009;76(4):330-343.

22. McConnell EA. Competence vs competency. Nurs Manage 2001;32(5):14. 